American Journal of Pharmacology and Toxicology 6 (2): 37-45, 2011

ISSN 1557-4962

(C) 2011 Science Publications

\title{
Acute and Sub-acute Toxicity of Crataegus Aronia Syn. Azarolus (L.) Whole Plant Aqueous Extract in Wistar Rats
}

\author{
Abdullah S. Shatoor \\ Department of Cardiology, College of Medicine, King Khalid \\ University, Abha 24121 Saudi Arabia
}

\begin{abstract}
Problem statement: Hawthorn comprises more than 200 species worldwide but very few species have been used medicinally. In Mediterranean region, the predominant species of the genus Crataegus is C. aronia syn. Azarolus (L). The extracts or tinctures prepared from the leaves, flowers and/or a fruit has been used traditionally for the treatment of different diseases including different cardiovascular problems. This species (C. aronia syn. Azarolus (L.)) has not been adequately studied. Thus, we aimed to investigate for the possible acute and sub-acute toxicity of $C$. aronia syn. Azarolus (L.) on Wistar albino rats. Approach: The phytochemical screening of the aqueous extract of C. aronia syn. Azarolus (L.) was determined. Athirty six Wistar rats of both sexes weighing 180$200 \mathrm{~g}$. were divided randomly into sex groups of 6 rats each. The first group was the control group and fed with equal volume of distilled water, while the other 5 groups were given single daily dose of the aqueous extract per os at different doses $\left(100,200,500,1000\right.$ and $\left.2000 \mathrm{mg} \mathrm{kg}^{-1}\right)$ for 28 days. The observation of acute toxicity and the sub-acute effects of the extract on the hematological, coagulation, liver function (LFT) and renal function parameters were reported. Results: The phytochemical screening of the aqueous extract of $C$. aronia syn. Azarolus (L) indicates the presence of flavonoids, terpenes/sterols, saponins and tannins. There were no signs of acute toxicity and no fatality. There was significant increase of the Red Blood Cell Count (RBC) and Packed Cell Volume (PCV) in rats given the extract at dose of $200 \mathrm{mg} \mathrm{kg}^{-1}$ but not with other doses. Furthermore, the prothrombin (PT) and Activated Partial Thromboplastin Times (APTT) were significantly increased in rats given the extract at doses of $100-500 \mathrm{mg} \mathrm{kg}$. There was no changes in the level of LFT, renal function and electrolytes. Conclusion: This study indicates that $C$. aronia syn. Azarolus (L.) whole plant aqueous extract has no acute or sub-acute adverse effects when administered under or equal to the dose of 2000 $\mathrm{mg} \mathrm{kg}{ }^{-1}$ body weight. The increase in the RBC, PCV as well as PT and APTT needs further studies.
\end{abstract}

Key words: Crataegus aronia, wistar rats sub-acute toxicity, crataegus aronia, whole plant, aqueous extract, hawthorn comprises, phytochemical screening, herbal remedies, laboratory animals, being listed

\section{INTRODUCTION}

Plants are one of the most important sources of active substances with therapeutic potential to cure a variety of diseases in humans (Gill et al., 2010; 2011). The evaluation of pharmacological effects can be used as a strategy for discovering new drugs of plant origin (Gill et al., 2011; Holloway et al., 2011). There is an ongoing world-wide revolution which is mainly premised on the belief that herbal remedies are safer and less damaging to the human body than synthetic drugs (Alam et al., 2011). According to World Health Organization about $80 \%$ of the world population relies on traditional medicine for primary health care and more than $30 \%$ of the plant species have been used medicinally. However, there is limited scientific evidence regarding the safety and efficacy to support the continued therapeutic application of these medicinal plants. Because of this renewed interest in herbal remedies and the increased use of plants extracts in food, cosmetics and pharmaceutical industries, there is a compelling need for thorough scientific safety evaluation of the medicinal plants (Ben-Arye et al., 2011; Haque and Haque, 2011).

Laboratory animals are sensitive to toxic substances occurring in plants. Hence, the administration of the extracts in increasing amounts enables the evaluation of the acute and sub-acute toxicity limits. Therefore, the test should be carried out for three doses and for both sexes, taking into account other factors such as age, weight, species, diet and environmental conditions (Silva et al., 2011). 
Hawthorn is deciduous and a member of the rosaceae family. The Hawthorn is native to Mediterranean region, North Africa, Europe and Central Asia. Most species of Hawthorn have prominent, long, straight and sharp thorn, ranging from 1-5 inches. Hawthorn comprises more than 200 species in the world. In Mediterranean region, the predominant species of genus Crataegus is C. aronia syn. Azarolus (L) that populates the mountains of these areas.

The extracts or tinctures prepared from the leaves, flowers and/or fruits from the genus Crataegus (Rosacea) dates back to ancient times (Jayachandran et al., 2010; Kanyonga et al., 2011). Currently, there is increasing use of different hawthorn species in cardiovascular diseases and being listed as herbal drugs in pharmacopoeias of countries, such as Germany, France, China and England particularly for the treatment of mild form of heart failure (Jayachandran et al., 2010; Kanyonga et al., 2011; Swaminathan et al., 2010). Furthermore, several ethnobotanical and ethnopharmacological surveys on the therapeutic use of indigenous plants have revealed that the indigenous member of this genus, Crataegus aronia syn. Azarolus (L) (Rosaceae) is used in the traditional Arab medicine to treat cardiovascular diseases, as well as cancer, diabetes and sexual weakness (Nawash and Al-Horani 2011).

Despite the extensive use of the plant, Crataegus aronia syn. Azarolus (L), has not been subjected to adequate studies including its acute and sub-acute toxicity. Motivated by this, we aimed at present to report the acute and sub-acute effects of the aqueous extract of Crataegus aronia syn. Azarolus (L) whole plant on biochemical indices of liver and kidney functions as well as some hematological parameters in albino Wistar rats, which will be a guidance for the planned future studies of its effect on different systems particularly the cardiovascular system.

\section{MATERIALS AND METHODS}

Preparation of the extract: This study was performed in the Research labs of Medical School of King Khalid University at Abha, Saudi Arabia. Crataegus aronia syn. Azarolus (L) whole plant was purchased from a local market in Jordan (Middle-east). The plant was identified and extracted by the Department of Pharmacognosy of college of Pharmacy at King Khalid University.

The dried plant was ground to a powder and extracted by maceration in distilled water $(1 \mathrm{~kg} / 1 \mathrm{~L}, \mathrm{w} / \mathrm{v})$ for 2 days at $37^{\circ} \mathrm{C}$ (Abdul et al., 2009). The extract was filtered and the excess water was evaporated under reduced pressure in a rotary evaporator. The resulting residue ( $28 \mathrm{~g}$ ) called the aqueous extract was stored at $4^{\circ} \mathrm{C}$. The residue was re-constituted in distilled water to obtain the various concentrations used in the study.

Phytochemical screening tests (I-VII): The phytochemical screening of the aqueous extract of the leaves Crataegus aronia was carried out according to the method of Evans (2000) and the method of Mogana et al., 2011). Qualitative analysis of alkaloids, flavonoids, glycosides, saponins and tannins were studied using freshly prepared ground samples of Crataegus aronia syn: Azarolus (L) whole plant extract.

Test for flavonoids: About $1.0 \mathrm{~mL}$ of $10 \%$ ferric chloride was added to $1.0 \mathrm{~mL}$ of extract. The formation of a greenish brown or black precipitate or color was positive test for phenolic nucleus. To $1.0 \mathrm{~mL}$ extract, $1.0 \mathrm{~mL}$ of dilute $\mathrm{NaOH}$ was added. Addition of $1.0 \mathrm{~mL}$ dilute $\mathrm{NaOH}$ to $1.0 \mathrm{~mL}$ extract gave a precipitate which shows presence of flavonoids.

Test for saponins: $1.0 \mathrm{~mL}$ of extract was boiled with $5.0 \mathrm{~mL}$ of distilled water for $5 \mathrm{~min}$ and decanted while still hot. The filtrate was used for the following tests:

- Frothing test: About $1.0 \mathrm{~mL}$ of the filtrate was diluted with $4.0 \mathrm{~mL}$ of distilled water shaken vigorously and observed on standing for stable froth which confirms the presence of saponins

- Emulsion test: About 2 drops of olive oil was added to $1.0 \mathrm{~mL}$ of filtrate. The solution was shaken and observed for formation of emulsion which confirms the presence of saponins

Test for tannins: About $5.0 \mathrm{~mL}$ of extract was added to $2.0 \mathrm{~mL}$ of $1 \% \mathrm{HCl}$. Deposition of a red precipitate was an evidence for the presence of phlobotannins.

Test for terpenes/sterols: Liebermann-Burchard's Test: $(200 \mathrm{mg}$ plant material in $10 \mathrm{~mL}$ chloroform, filtered; $2 \mathrm{~mL}$ filtrate $+2 \mathrm{~mL}$ acetic anhydride $+1 \mathrm{~mL}$ of conc. $\mathrm{H}_{2} \mathrm{SO}_{4}$. A blue-green ring indicates the presence of terpenes/sterols.

Test for free anthraquinones: The Borntrager's test for anthraquinones was used. $5 \mathrm{mg}$ of the plant extract was shaken with $10 \mathrm{~mL}$ of benzene, filtered and $5 \mathrm{ml}$ of $10 \%$ ammonia solution added to the filtrate and the mixture shaken.

Combined anthraquinones: $5 \mathrm{mg}$ of plant extract was boiled with $10 \mathrm{~mL}$ aqueous sulphuric acid and filtered while hot. The filtrate was shaken with $5 \mathrm{~mL}$ of benzene, the benzene layer separated and half its own volume of $10 \%$ ammonia solution added. 
Test for cardiac glycoside: About $5.0 \mathrm{~mL}$ of extract was treated with $2.0 \mathrm{~mL}$ of glacial acetic acid containing 1 drop of $0.1 \%$ ferric chloride and then mixed with $1.0 \mathrm{~mL}$ concentrated sulphuric acid. A brown ring of the interface indicates a deoxysugar characteristic of cardenolides.

Test for alkaloids: About $1.0 \mathrm{~mL}$ of extract of the sample was added and shaken with $5.0 \mathrm{~mL}$ of $2 \% \mathrm{HCl}$ on a steam bath and filtered. Five drops of Meyer's reagent (potassium mercuric iodide solution) was then added to $1.0 \mathrm{~mL}$ of the filtrate and observed for cream colored precipitate which is a positive test for alkaloids.

Experimental animals: About 36 Wistar strain rats of both sexes weighing between 50.7-60.9g were procured from a random bred colony in the animal house of College of Medicine of King Khalid University, Abha, Saudi Arabia. The rats were caged in plastic cages (6/cage) in a controlled environment (ambient temperature, $27.0 \pm 2.0^{\circ} \mathrm{C}$ and with a $12 \mathrm{~h} \mathrm{light/darkness}$ cycle). They were allowed to acclimatize for 10 weeks during which the weight gained was between 180-200 g. During this period the rats were fed on rats-chow diets and water ad-libitum. The experiments performed complied with the rules of the Institute of Laboratory Animal Resources, Commission on Life Sciences, National Research Council and approved by the Ethical Committee of the King Khalid University.

Acute toxicity study: Acute toxicity bioassay was conducted according to the World Health Organization guideline for the evaluation of safety and efficacy of herbal medicines (WHO, 1993). The rats were divided into six groups of six animals each. The aqueous extract of Crataegus aronia was administrated per os to rats of groups 2-6 in a single dose/day of 100, 200, 500, 1000, $2000 \mathrm{mg} \mathrm{kg}^{-1}$ body weight (bwt) respectively by intra gastric gavages using a feeding needle. The control group (group 1) received an equal volume of distilled water as vehicle.

Observations of acute toxic symptoms were made and recorded systematically 1, 2, 4, 6 and $24 \mathrm{~h}$. after administration of the extract. The number of rats that survived were noted after $24 \mathrm{~h}$ and then maintained for the further 3 days with daily observations. This visual observation included skin changes, mobility and aggressiveness, sensitivity to sound and pain, as well as respiratory movements. The acute toxic effects of the extract were assessed on the basis of mortality, which was expressed as LD50. Lethal dose
(LD 50) was calculated using the following equation (Turner and Hebborn, 1965):

LD50 $=$ the apparent least dose lethal to all in a group $-\sum$ $(\mathrm{a} \times \mathrm{b}) / \mathrm{N}$ :

Sub-acute toxicity study: The extract was administered in a manner similar to that used in acute toxicity study with same doses to the animals for 28 days (Ozolua et al., 2010).

Collection and analyses of blood: At the end of the experiment, all animals were anaesthetized with diethylether vapor. Blood samples were collected by cardiac puncture into three sets of plain, EDTA treated and sodium citrate tubes. The blood in the plain and sodium citrate tubes were allowed to clot. The clotted blood samples in the plain tubes were spun in a bench top centrifuge ( $3000 \mathrm{rpm}$ for $10 \mathrm{~min}$ ) to obtain sera. The separated serum samples from the plain tubes were stored in the refrigerator until required for the biochemical analyses. The serum biomarkers analyzed include: Alanine Amino Transferase (ALT), aspartate amino transferase (AST), total bilirubin, total proteins, Urea, Creatinine, potassium $(\mathrm{K}+)$, sodium $(\mathrm{Na}+)$ and chloride $(\mathrm{Cl}-)$. These tests were assayed using commercial available kits according to the manufacture's instruction. Blood sample collected in EDTA treated tubes were used for Full Blood Count (FBC), which included: Total Erythrocytes Count (TEC), Hgb, PCV, MCV, MCH, MCHC, Platelets Count (PLC) and Total Leucocytes Count (T LC). The FBC was analyzed using Automated Hematology System (Sysmex HematologyCoagulation Systems ${ }^{\circledR}$, Model KX-21N, Sysmex Incorporation, Kobe, Japan).

Determination of clotting time: The blood collected directly from the heart to avoid contamination with tissue thromboplastin $(200 \mu \mathrm{L} \mathrm{mL}$ from each rat). At every time, the blood was delivered into four glass test tubes that had previously been warmed and maintained at $37^{\circ} \mathrm{C}$ and the tubes immediately placed in a $37^{\circ} \mathrm{C}$ water bath to mimic the temperature of the internal environment. The glass test tubes were continually tilted at 10s intervals until blood stopped flowing when tilted at an angle of $90^{\circ}$. The period in seconds was recorded from the time the blood is delivered into the glass test tubes until it stops flowing when tilted at an angle of $90^{\circ}$ using stopwatch. 
Determination of Prothrombin Time (PT): Blood was collected into sample vials containing 3.2\% sodium citrate (as specified in the Prothrombin Time (PT) test kit used) in the ratio 1: 9 with the blood sample. The blood was then centrifuged at $1000 \mathrm{~g}$ for $15 \mathrm{~min}$. to obtain platelet poor plasma. Thromboplastin

PT-S was placed in a water bath at $37^{\circ} \mathrm{C}$ and 0.1 $\mathrm{mL}$ of test plasma was also put into a test tube and placed in the water bath to prewar to $37^{\circ} \mathrm{C}$. A $0.2 \mathrm{~mL}$ of warmed thromboplastin PT-S was then forcibly added to the test plasma and the stopwatch was started. The tube was tilted repeatedly until a clot was formed and the time taken for clot to form was noted. Precaution was taken to perform the test within $3 \mathrm{~h}$ of blood collection.

Determination of Activated Partial Thromboplastin Time (APTT): A mixture of $0.1 \mathrm{~mL}$ of plasma with 0.1 $\mathrm{mL}$ of APTT reagent containing Cephalin-Kaolin suspension was incubated at $37^{\circ} \mathrm{C}$ for $5 \mathrm{~min}$, followed by the addition of $0.1 \mathrm{~mL}$ of $0.025 \mathrm{M} \mathrm{CaCl}_{2}$ solution. APTT was taken as the interval between the addition of $\mathrm{CaCl}_{2}$ and the moment when the fibrin clot was visually detected. The blood tests were done by an expert technicians in the fields and were unaware of the detailed treatment groups.

Statistical analysis: The results were expressed as the mean value \pm SD. Statistical differences between groups were assessed using the SPSS software, version 16 and the Student's t-test was used to determine the difference between groups and $p<0.05$ denoted statistical significance.

\section{RESULTS}

The results of this study are shown in Table 1-5. In this study, the oral administration of the aqueous extract of Crataegus aronia at all given doses (up to $2000 \mathrm{mg} \mathrm{kg}$ ) did not produce any visible sign of acute toxicity or instant death in rats tested during the period of observation.

Preliminary phytochemical screening of the Crataegus aronia aqueous extract indicates the presence of flavonoids, terpenes/sterols, saponins and tannins, while anthraquinones (free and combined), glycosides and alkaloids were not detected (Table 2).

The effect of $C$. aronia aqueous whole plant extract on hematological parameters is depicted in (Table 3). The Red Blood Cells count (RBC's) and hematocrit value increased significantly $(p<0.05)$ on administration of the extract to both male and female rats only at dose of $200 \mathrm{mg} \mathrm{kg}^{-1}$. However, there was no reduction in any other hematological parameters with the use of higher doses of the extract.

Table 4 summarizes the effect of the extract on the haemostatic parameters used in this study: There were significant increase in the Clotting time, PT and APTT with the highest changes being observed in the rats which received the extract at a doses of 100, 200 and $500 \mathrm{mg} \mathrm{kg}^{-1}$ body weight.

There were no significant changes in the serum levels of ALT, AST, total bilirubin, total protein, creatinine, urea, $\mathrm{Na}^{+}, \mathrm{K}^{+}$and $\mathrm{Cl}^{-}$with any given doses compared to the control levels (Table 5).

Table 1: LD50 determination by arithmetic method of Karbar

\begin{tabular}{|c|c|c|c|c|c|}
\hline Groups & Number of rats & No. of animals dead & Dose difference (a) & Mean mortality (b) & Probit $(a \times b)$ \\
\hline Control group & 6 & 0 & 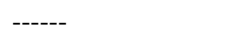 & & \\
\hline C. aronai $100 \mathrm{mg} \mathrm{kg}^{-1}$ & 6 & 0 & 100 & ------ & ------ \\
\hline C. aronai $200 \mathrm{mg} \mathrm{kg}^{-1}$ & 6 & 0 & 100 & ------ & ------ \\
\hline C. aronai $500 \mathrm{mg} \mathrm{kg}^{-1}$ & 6 & 0 & 400 & ------ & ------ \\
\hline C. aronai $1000 \mathrm{mg} \mathrm{kg}^{-1}$ & 6 & 0 & 500 & ------ & ----- \\
\hline C. aronai $2000 \mathrm{mg} \mathrm{kg}^{-1}$ & 6 & 0 & 1000 & ------ & ----- \\
\hline
\end{tabular}

Table 2: Phytochemical screening of Crataegus aronia syn. Azarolus (L) aqueous extract

\begin{tabular}{ll}
\hline Chemical compound & Observations \\
\hline Flavonoids & A reddish color was observed \\
1- Frothing test & \\
2- Emulsion test & A stable froth was observed \\
Tannins & An emulsion is formed \\
Terpenes/sterol & Blue black color was observed \\
Free anthraquinones & A reddish brown ring was observed at the interface \\
Combined anthraquinones & Gold color was not observed on the ammoniacal phase \\
Cardiac glycosides & No pink, red or violet color was observed on the ammoniacal phase \\
Alkaloids & No reddish brown ring was observed at the interface \\
\hline
\end{tabular}


Am. J. Pharm. \& Toxicol., 6 (2): 37-45, 2011

Table 3: Effect of oral administration of Crataegus aronia aqueous extract on hematological parameters in all groups of rats

\begin{tabular}{lcccccc}
\hline Parameter & $\begin{array}{l}\text { Control group } \\
\left(100 \mathrm{mg} \mathrm{kg}^{-1}\right)\end{array}$ & $\begin{array}{l}\text { C. aronia } \\
\left(200 \mathrm{mg} \mathrm{kg}^{-1}\right)\end{array}$ & $\begin{array}{l}\text { C. aronia } \\
\left(500 \mathrm{mg} \mathrm{kg}^{-1}\right)\end{array}$ & $\begin{array}{l}\text { C. aronia } \\
\left(500 \mathrm{mg} \mathrm{kg}^{-1}\right)\end{array}$ & $\begin{array}{l}\text { C. aronia } \\
\left(1000 \mathrm{mg} \mathrm{kg}^{-1}\right)\end{array}$ & $\begin{array}{l}\text { C. aronia } \\
\left(2000 \mathrm{~kg}^{-1}\right)\end{array}$ \\
\hline Number of rats & 6 & 6 & 6 & 6 & 6 & 6 \\
RBC's $\left(\times 10^{6}\right)$ & $8.41 \pm 0.33$ & $7.94 \pm 0.12$ & $9.39 \pm 0.65^{*}$ & $7.48 \pm 0.43^{*}$ & $8.49 \pm 0.88$ & $8.31 \pm 0.60$ \\
Hb $(\mathrm{g} / \mathrm{dl})$ & $15.0 \pm 0.700$ & $15.10 \pm 0.56$ & $15.93 \pm 1.07$ & $13.78 \pm 0.46$ & $14.92 \pm 0.89$ & $14.28 \pm 0.69$ \\
Hct $(\%)$ & $47.28 \pm 1.60$ & $46.63 \pm 3.21$ & $51.45 \pm 2.96^{*}$ & $47.12 \pm 1.32$ & $48.35 \pm 1.64$ & $46.62 \pm 2.65$ \\
MCV $(\mathrm{fL})$ & $56.21 \pm 1.98$ & $58.72 \pm 0.91$ & $54.79 \pm 0.78$ & $62.99 \pm 1.84^{*}$ & $56.94 \pm 3.94$ & $58.30 \pm 2.27$ \\
MCH $(\mathrm{pg})$ & $17.83 \pm 0.33$ & $18.34 \pm 0.67$ & $16.95 \pm 0.058$ & $18.45 \pm 0.59$ & $17.65 \pm 0.91$ & $19.52 \pm 0.78^{*}$ \\
MCHC (pg/dl) & $31.72 \pm 0.96$ & $32.38 \pm 1.10$ & $29.07 \pm 0.24$ & $29.24 \pm 0.60$ & $30.86 \pm 1.10$ & $33.50 \pm 0.84^{*}$ \\
PLT $\left(\times 10^{3}\right)$ & $313.9 \pm 21.40$ & $352.25 \pm 25.4$ & $339.50 \pm 23.1$ & $348.25 \pm 10.2$ & $326.24 \pm 12.8$ & $545.00 \pm 29.2^{*}$ \\
WBC's $\left(\times 10^{3}\right)$ & $11.89 \pm 1.20$ & $11.20 \pm 1.33$ & $11.86 \pm 1.25$ & $10.79 \pm 2.76$ & $11.77 \pm 1.18$ & $11.10 \pm 2.18$ \\
\hline
\end{tabular}

*: Values are statistically significant at $\mathrm{p}<0.05$ when compared to control group

Table 4: Effect of oral administration of Crataegus aronia aqueous extract on clotting time, PT and APTT in all groups of rats

\begin{tabular}{lllll}
\hline Parameter & Number of rats & Clotting time $(\mathrm{sec})$ & PT $(\mathrm{sec})$ & APTT $(\mathrm{sec})$ \\
\hline Control group & 6 & $51.25 \pm 4.03 \pm$ & $13.13 \pm 1.03$ & $27.07 \pm 0.700$ \\
C. aronia $\left(100 \mathrm{mg} \mathrm{kg}^{-1}\right)$ & 6 & $88.50 \pm 6.13^{*}$ & $12.97 \pm 0.759$ & $31.98 \pm 1.75^{*}$ \\
C. aronia $\left(200 \mathrm{~g} \mathrm{~kg}^{-1}\right)$ & 6 & $82.75 \pm 4.79^{*}$ & $18.30 \pm 1.02^{*}$ & $38.68 \pm 1.09^{*}$ \\
C. aronia $\left(500 \mathrm{~m} \mathrm{~kg}^{-1}\right)$ & 6 & $63.75 \pm 4.99^{*}$ & $14.57 \pm 1.00^{*}$ & $30.90 \pm 2.64^{*}$ \\
C. aronia $\left(1000 \mathrm{~m} \mathrm{~kg}^{-1}\right)$ & 6 & $52.75 \pm 1.70$ & $13.26 \pm 0.34$ & $25.42 \pm 0.66$ \\
C. aronia $\left(2000 \mathrm{mg} \mathrm{kg}^{-1}\right)$ & 6 & $51.25 \pm 4.03$ & $13.45 \pm 0.500$ & $25.40 \pm 0.66$ \\
\hline
\end{tabular}

*: Values are statistically significant at $\mathrm{p}<0.05$ when compared to control group

Table 5: Effect of acute oral administration of Crataegus aronia aqueous extract on some serum biochemical parameters of rats

\begin{tabular}{|c|c|c|c|c|c|c|}
\hline Parameter & Control & $\begin{array}{l}\text { C. aronia } \\
100 \mathrm{mg} \mathrm{kg}^{-1} \\
\end{array}$ & $\begin{array}{l}\text { C. aronia } \\
200 \mathrm{mg} \mathrm{kg}^{-1}\end{array}$ & $\begin{array}{l}\text { C. aronia } \\
500 \mathrm{mg} \mathrm{kg}^{-1}\end{array}$ & $\begin{array}{l}\text { C. aronia } \\
1000 \mathrm{mg} \mathrm{kg}^{-1}\end{array}$ & $\begin{array}{l}\text { C. aronia } \\
2000 \mathrm{mg} \mathrm{kg}^{-1}\end{array}$ \\
\hline Number of rats & 6 & 6 & 6 & 6 & 6 & 6 \\
\hline ALT (U/L) & $37.64 \pm 1.36$ & $37.36 \pm 1.36$ & $36.32 \pm 1.48$ & $36.34 \pm 1.58$ & $37.82 \pm 2.24$ & $36.2 \pm 1.17$ \\
\hline $\mathrm{AST}(\mathrm{U} / \mathrm{L})$ & $86.6 \pm 2.61$ & $84.6 \pm 3.21$ & $85.2 \pm 1.92$ & $86.4 \pm 4.04$ & $86.4 \pm 4.50$ & $83.6 \pm 4.56$ \\
\hline Total protein $\left(\mathrm{mg} \mathrm{dL}^{-1}\right)$ & $6.94 \pm 0.11$ & $6.72 \pm 0.38$ & $6.76 \pm 0.40$ & $6.88 \pm 0.20$ & $6.84 \pm 0.05$ & $6.84 \pm 0.27$ \\
\hline Total bilirubin $\left(\mathrm{mg} \mathrm{dL}^{-1}\right)$ & $0.5 \pm 0.0232$ & $0.49 \pm 0.02$ & $0.488 \pm 0.19$ & $0.486 \pm 0.019$ & $0.484 \pm 0.020$ & $0.494 \pm 0.021$ \\
\hline Urea $\left(\mathrm{mg} \mathrm{dL}^{-1}\right)$ & $46.06 \pm 2.58$ & $45.74 \pm 1.98$ & $45.8 \pm 3.69$ & $46.26 \pm 2.38$ & $46.76 \pm 1.50$ & $46.08 \pm 2.49$ \\
\hline Creatinine $\left(\mathrm{mg} \mathrm{dL}^{-1}\right)$ & $0.45 \pm 0.016$ & $0.442 \pm 0.033$ & $0.436 \pm 0.019$ & $0.442 \pm 0.019$ & $0.454 \pm 0.021$ & $0.44 \pm 0.029$ \\
\hline $\mathrm{Na}^{++}\left(\mathrm{mmol} \mathrm{L}^{-1}\right)$ & $139.75 \pm 0.96$ & $140.75 \pm 1.5$ & $138.25 \pm 1.70$ & $142 \pm 5.66$ & $141.33 \pm 2.52$ & $140.33 \pm 3.06$ \\
\hline $\mathrm{K}^{+}\left(\mathrm{mmol} \mathrm{L}^{-1}\right)$ & $4.65 \pm 0.33$ & $5.125 \pm 0.88$ & $4.675 \pm 0.54$ & $4.73 \pm 0.25$ & $4.825 \pm 0.28$ & $5.067 \pm 0.75$ \\
\hline $\mathrm{Cl}^{-}\left(\mathrm{mmol} \mathrm{L}{ }^{-1}\right)$ & $99.25 \pm 0.96$ & $103.75 \pm 2.87$ & $101.75 \pm 1.5$ & $105.66 \pm 2.89$ & $101.75 \pm 1.5$ & $99.3 \pm 4.16$ \\
\hline
\end{tabular}

*: Values are statistically significant at $\mathrm{p}<0.05$ when compared to control group

\section{DISCUSSION}

Investigation of the acute toxicity is the first step in the toxicological investigation of an unknown substance. The index for the acute toxicity is the LD50. The results in this study showed that the acute administration of the aqueous extract of Crataegus aronia at all given doses (up to $2000 \mathrm{mg} \mathrm{kg}^{-1}$ ) did not produce any sign of acute toxicity or instant death in rats tested during the period of observation. This, however, suggest that the extract has no acute toxicity when administered orally and the lethal dose if any is above $2000 \mathrm{mg} \mathrm{kg}^{-1}$. Clarke et al. (1975) showed that substances with LD50 of $1000 \mathrm{mg} \mathrm{kg}^{-1}$ body weight given orally are considered safe or of low toxicity. Similarly, the chemical labeling and classification of acute systemic toxicity based on oral LD50 values recommended by the Organization for Economic Cooperation and Development (OECD, Paris, France)
(Walum, 1998) are as follow: very toxic, $<5 \mathrm{mg} \mathrm{kg}^{-1}$; toxic, $>5<50 \mathrm{mg} \mathrm{kg}^{-1}$; harmful, $>50<500 \mathrm{mg} \mathrm{kg}^{-1}$ and no label, $>500<2000 \mathrm{mg} \mathrm{kg}^{-1}$. Therefore, the expected high LD50 (>2000 mg kg-1 body weight) of the aqueous extract Crataegus aronia, is an indication that the extract could be considered relatively safe especially when administered orally where absorption may not be complete due to inherent factors limiting absorption in the gastro intestinal tract. Although, obtaining a lethal dose in animals may not predict the human lethal dose of a drug or acute poisoning overdose (Chapman et al., 2010). However, it is usually used to provide a guideline for selecting doses for the sub-acute dosage for future clinical relevance.

Preliminary phytochemical screening carried out in this study indicated that Crataegus aronia syn: Azarolus (L) contain mainly flavonoids, tanninis, saponins, Trepens and sterols in its aqueous extract. These phytochemicals are known to perform several 
general and specific functions in plants and may exhibit different biochemical and pharmacological actions in different species of animals when ingested. These actions range from cell toxicity to cell protective effects. Similar phytochemical findings are present in other Crataegus species like $C$. monogyna and $C$. laevigata (Barros et al., 2011; Jayachandran et al., 2010).

The various biochemical and hematological parameters investigated in this study are useful indices of evaluating the toxicity of plant extract in animals. Assessment of hematological parameters can be used to determine the extent of deleterious effect of foreign compounds including plant extracts on the blood constituents of an animal. It can also be used to explain blood relating functions of chemical compounds and plant extracts (Soa et al., 2011). Such analysis is relevant to risk evaluation as the change in hematological system has higher predictive value for human toxicity, when the data are translated from animal studies.

The various blood cells (erythrocytes, leucocytes and platelets) produced at a turnover rate of about 1 to 3 million per second in a healthy human adult and this value could be altered in certain physiological or pathological states (Guyton and Hall, 2000). Certain drugs including alkylating cytotoxic agents affect blood formation rate and the normal range of hematological parameters (Zuk et al., 2011).

The results of the hematological parameters of the present study did not show any worrisome results since all the changes were within the normal expected range for the rat species used in this study. However, there was an important observation which might be interesting. The RBC and PCV values were significantly higher among the group of rats treated with the extract at dose of $200 \mathrm{mg} \mathrm{kg}^{-1}$ compared to the other groups treated with different doses. These values were above the well established reference ranges for Wistar rats (Cameron and Watson, 1949). The reason for this change with this dose $\left(200 \mathrm{mg} \mathrm{kg}^{-1}\right)$ is not clear, however, this could be due to variations in the absorption, bioavailability and metabolism of the antioxidants (flavonoids) present in the extract (Prochazkova et al., 2011; Amran et al., 2010). Hawthorn extract is well known rich source for flavonoids which include: hyperoside, isoquercitrin, epicatechin, chlorogenic acid, quercetin, rutin and protocatechuic acid (Barros et al., 2011). In the present study, the phytochemical screening confirmed the presence of flavonoids in the aqueous extract $C$. aronia. Thus, the possible mechanism of the increase in RBC and PCV values involves the effect of flavonoids on maintaining the cell membrane through inhibition of peroxidation of polyunsaturated fatty acids (Wang et al., 2009; Hasan et al., 2009). Also, flavonoids are capable to inhibit the formation of superoxide ions and hydroxy radicals, which are two strong peroxidation agents that are produced in the body under normal conditions and cause destruction of cells (Esmaeili and Sonboli, 2010). Therefore, flavonoids may protect both the hematopoietic committed stem cells and the formed blood cells from the attack of the reactive free radicals. Furthermore, the antioxidant activity of flavonoids may maintains the haeme iron in its ferrous state and this could enhance erythropoiesis. Whether the aqueous extract of $C$. aronia has any effects on the level of erythropoietin remains to be established.

The aqueous extract of $C$. aronia exhibited anticoagulant activities by increasing clotting times, PT and APTT. APTT and PT are a qualitative measurement of factors involved in the intrinsic and extrinsic pathways respectively (Salawu et al., 2008; Bamidele et al., 2010; Cipil et al., 2009). The increase in APTT and/or PT could be due to, a deficiency of, or an inhibitor to, any of the clotting factors involved in either pathways or in the final step of the clotting pathway (Abdullah et al., 2010). The observed increase in clotting time, PT and APTT occurred at a doses between $100-500 \mathrm{mg} \mathrm{kg}^{-1}$ but not with higher doses indicate that this effect is probably not a toxicity and may have a therapeutic potential as anticoagulant and warrant further investigation.

Many xenobiotics are capable of causing some degree of liver injury (Omiecinski et al., 2011). The liver is prone to xenobiotic-induced injury because of its central role in xenobiotic metabolism, its portal location within the circulation and its anatomic and physiologic structure. Generally, analysis of the activities of some basic liver enzymes in the plasma or serum can be used to indirectly assess the integrity of tissues after being exposed to certain pharmacological agent (s) (Al-Hashem, 2009). These enzymes are the usual liver markers whose plasma concentrations above the homeostatic limits could be associated with various forms of disorders which affect the functional integrity of the liver tissue. In the assessment of liver damage by drugs or any other hepatotoxin, the determination of enzyme levels such as ALT and AST is largely used (Ramaiah, 2011). Necrosis or membrane damage releases the enzyme into circulation; therefore, it can be measured in the serum. High levels of AST indicate liver damage. ALT catalyses the conversion of alanine to pyruvate and glutamate and is released in a similar manner. Therefore, ALT is more specific to the liver and is 
thus a better parameter for detecting liver injury (Ozer $e t$ al., 2008). The results of the liver enzymes (ALT and AST) as well as bilirubin suggest that Crataegus aronia is not a hepatotoxic at all doses used in our study.

Bilirubin is formed by the breakdown of hemoglobin in the liver, spleen and bone marrow. An increase in tissue or serum bilirubin concentrations occurs as a result of increased breakdown of RBC (haemolysis) or liver damage e.g., hepatitis or bile duct obstruction. The normal levels of serum bilirubin concentrations at all doses of the extract used in this study are indicative of non-adverse effects of the extract on haemoglobin metabolism pathways.

The Kidneys are highly susceptible to toxicants for two reasons; A high volume of blood flows through it and its ability to filter large amounts of toxins which can concentrate in the kidney tubules. It can result in systemic toxicity causing: decreased ability to excrete body wastes, inability to maintain body fluid and electrolyte balance and decreased synthesis of essential hormones. Blood urea nitrogen is derived in the liver protein / amino acid from diet or tissue sources and is normally excreted in the urine. In renal disease, the serum urea accumulates because the rate of serum urea production exceeds the rate of clearance (Mayne and Mayne, 1994). Creatinine, on the other hand, is mostly derived from endogenous sources by tissue creatinine breakdown. The plasma creatinine concentrations in normal individuals are usually affected by a number of factors such as the muscle mass, high protein diet and catabolic state, thus serum urea concentration is often considered the more reliable renal function predictor than serum creatinine. In the present study there was no significant changes in the levels of creatinine, urea, $\mathrm{Na}^{++}$, $\mathrm{K}^{+}$and $\mathrm{Cl}^{-}$in the sera of all rats treated with different doses of the aqueous extract of $C$. aronia and therefore considered non nephrotoxic.

\section{CONCLUSION}

The Data of the present study do suggest that the whole plant aqueous extract of Crataegus aronia syn: Azarolus (L) is not toxic under a dose less than or equal to $2000 \mathrm{mg} \mathrm{kg}^{-1}$. The extract may possess hematopoietic and anticoagulant potentials at a doses between 100-500 $\mathrm{mg} \mathrm{kg}^{-1}$ and warrants further investigations.

\section{ACKNOWLEDGEMENT}

I would like to express my sincere gratitude and appreciation to the research deanship-king Khalid University for their financial support and Prof. Hesham Soliman, College of Pharmacy-King Khalid University for his technical support.

\section{REFERENCES}

Abdul, K.M., G.S. Krushna, S.A. Hussain and K.L. Devi, 2009. Effect of aqueous extract of nutmeg on hyperglycaemia, hyperlipidaemia and cardiac histology associated with isoproterenol-induced myocardial infarction in rats. Tropical, J. Pharmaceutical, Res., 8: 337-344.

Abdullah, W.Z., S.K. Moufak, Z. Yusof, M.S. Mohamad and I.M. Kamarul, 2010. Shortened activated partial thromboplastin time, a hemostatic marker for hypercoagulable state during acute coronary event. Transl. Res., 155: 315-319. PMID: 20478546

Alam, M.B., M.S. Hossain, N.S. Chowdhury, M.E.H. Mazumder and M.E. Haque et al., 2011. In vitro and in vivo antioxidant and toxicity evaluation of different fractions of Oxalis corniculata linn. J. Pharmacol. Toxicol., 6: 337-348.

Al-Hashem, F., 2009. Camel's milk protects against aluminum chloride-induced toxicity in the liver and kidney of white albino rats. Am. J. Biochem. Biotechnol., $\quad$ 5: $\quad 98-108 . \quad$ DOI: 10.3844/ajbbsp.2009.98.108

Amran, A.A., Z. Zakaria, F. Othman and O. Morat, 2010. Effect of garcinia atroviridis on oxidative stress and atherosclerotic changes in experimental guinea pigs. Am. J. Pharmacol. Toxicol., 5: 65-70. DOI: 10.3844/ajptsp.2010.65.70

Bamidele, O., A.M. Akinnuga, M.M.C. Anyakudo, O.A. Ojo and G.B. Ojo et al., 2010. Haemostatic effect of methanolic leaf extract of Ageratum conyzoides in albino rats. J. Med. Plants Res., 4: 2075-2079.

Barros, L., A.M. Carvalho and I.C.F.R. Ferreira, 2011. Comparing the composition and bioactivity of Crataegus monogyna flowers and fruits used in folk medicine. Phytochem. Anal.. 22: 181-188. DOI: 10.1002/pca.1267

Ben-Arye, E.B., E. Lev, Y. Keshet and E. Schiff, 2011. Integration of herbal medicine in primary care in Israel: A Jewish-Arab cross-cultural perspective. Evidence, Based, Complementary Alternativ Med. 2011: 1-8. DOI: 10.1093/ecam/nep146

Cameron, D.G. and G.M. Watson, 1949. The blood counts of the adult albino rat. Blood, 4: 816-818. PMID: 18150158

Chapman, K., S. Cretona, H. Kupferschmidtb, G.R. Martin and F. Wilksd et al., 2010. The value of acute toxicity studies to support the clinical management of overdose and poisoning: A crossdiscipline consensus. Regulatory Toxicol. Pharmacol., 58: 354-359. 10.1016/j.yrtph.2010.07.003 
Cipil, H.S., A. Kosar, A. Kaya, B. Uz and I.C. Haznedaroglu et al., 2009. In vivo hemostatic effect of the medicinal plant extract ankaferd blood stopper in rats pretreated with warfarin. Clin. Appl. Throm., Hemost., 15: 270-276. DOI: 10.1177/1076029608329578

Clarke, E.G.C., M.L. Clarke and R.J. Garner, 1975. Veterinary Toxicology. 1st Edn., Baillière Tindall, London, ISBN: 0702005568, pp: 438.

Esmaeili, M.A. and A. Sonboli, 2010. Antioxidant, free radical scavenging activities of Salvia brachyantha and its protective effect against oxidative cardiac cell injury. Food Chem. Toxicol., 48: 846-853. DOI: 10.1016/J.FCT.2009.12.020

Evans, W.C., 2002. Trease and Evans Pharmacognosy. 15th Edn., Bailiere Tindall W.B. Sauders Company Ltd, London, ISBN: 10: 0702026174, pp: 600

Gill, N.S., J. Bajwa, K. Dhiman, P. Sharma and S. Sood et al., 2011. Evaluation of therapeutic potential of traditionally consumed Cucumis melo seeds. Asian, J. Plant Sci., 10: 86-91. DOI: 10.3923/ajps.2011.86.91

Gill, N.S., P. Sharma, J. Bajwa, K. Dhiman and S. Sood et al., 2010. Study on Cucumis melo var. utilissimus seeds for the therapeutic potential. J. Plant, Sci., 5: 248-255.

Guyton, A.C. and J.E. Hall, 2000. Textbook of Medical Physiology. 10th Edn., Saunders, Philadelphia, ISBN-10: 072168677X, pp: 1064

Haque, M. and K. Haque, 2011. Sub-acute toxicity study of a novel compound E-Octadec-7-en-5ynoic acid from Capparis zeylanica linn roots. Agric. Biol. J. N. Am., 2: 708-712. DOI: 10.5251/abjna.2011.2.4.708.712

Hasan, S.M.R., M. Jamila, M.M. Majumder, R. Akter and M. Hossain et al., 2009. Analgesic and antioxidant activity of the hydromethanolic extract of Mikania scandens (L.) Willd. Leaves. Am. J. Pharmacol. Toxicol., 4: 1-7. DOI: 10.3844/ajptsp.2009.1.7

Holloway, C.A., C.J. Matthws, Y.C. Jeong, M.G. Moloney and C.F. Roberts et al., 2011. Novel chiral skeletons for drug discovery: Antibacterial tetramic acids. Chem. Biol. Drug Design, 78: 229235. DOI: 10.1111/j.1747-0285.2011.01133.x

Jayachandran, K.S., M. Khan, K. Selvendiran, S.N. Devaraj and P. Kuppusamy, 2010. Crataegus oxycantha extract attenuates apoptotic incidence in myocardial ischemia-reperfusion injury by regulating Akt and HIF-1 signaling pathways. J. Cardiovasc, Pharmacol., 56: 526-531. PMID: 20729753
Kanyonga, M.P., M.Y.A. Faouzi, A. Zellou, M. Essassi and Y. Cherrah, 2011. Effects of methanolic extract of Crataegus oxyacantha on blood homeostasis in rat. J. Chem., Pharm., Res., 3: 713717.

Mayne, P. and P.D. Mayne, 1994. Clinical Chemistry in Diagnosis and Treatment. 6th Edn., A Hodder Arnold Publication, London, ISBN-10: 0340576472, pp: 478.

Mogana, R., K. Teng-Jin and C. Wiart, 2011. In vitro antimicrobial, antioxidant activities and phytochemical analysis of Canarium patentinervium Miq. from Malaysia. Biotechnol., Res., Int., 2011: $768673 . \quad$ DOI: $10.4061 / 2011 / 768673$

Nawash, O.S. and A.S. Al-Horani, 2011. The most important medicinal plants in Wadi Araba desert in South West Jordan: A review article. Adv. Environ. Biol., 5: 418-425.

Omiecinski, C.J., P.J.V. Heuvel, G.H. Perdew and J.M. Peters, 2011. Xenobiotic metabolism, disposition, and regulation by receptors: From biochemical phenomenon to predictors of major toxicities. Toxicol., Sci., 120: S49-S75. DOI: 10.1093/toxsci/kfq338

Ozer, J., M. Ratnerb, M. Shawc, W. Baileya and S. Schomaker, 2008. The current state of serum biomarkers of hepatotoxicity. Toxicology, 245: 194-205. DOI: 10.1016/J.TOX.2007.11.021

Ozolua, R.I. , S. E. Idogun and G. E. Tafamel, 2010. Acute and sub-acute toxicological assessment of aqueous leaf extract of Bryophyllum pinnatum (Lam.) in sprague-dawley rats. Am. J. Pharmacol. Toxicol., 5: 145-151. DOI: 10.3844/ajptsp.2010.145.151

Prochazkova, D., I. Bousovab and N. Wilhelmova, 2011. Antioxidant and prooxidant properties of flavonoids. Fitoterapia, 82: 513-523. DOI: 10.1016/j.fitote.2011.01.018

Ramaiah, S.K., 2011. Preclinical safety assessment: Current gaps, challenges and approaches in identifying translatable biomarkers of drug-induced liver. Clin. Laboratory Med., 31: 161-172. DOI: 10.1016/j.cll.2010.10.004

Salawu, O.A., M. Aliyu and A.Y. Tijani, 2008. Haematological studies on the ethanolic stem bark extract of Pterocarpus erinaceus poir (fabaceae). African J. Biotechnol., 7: 1212-1215.

Silva, M.G.B., T.P. Aragaoa, C.F.B. Vasconcelosa, P. A. Ferreirab and B.A. Andradeb et al., 2011. Acute and subacute toxicity of Cassia occidentalis L. stem and leaf in Wistar rats. J. Ethnopharmacol., 136: 341-346. DOI: 10.1016/j.jep.2011.04.070 
Soa, O., A. E. A. Oaa and A. Dab, 2011. Antidiabetic and haematological effect of aqueous extract of stem bark of Afzelia africana (Smith) on streptozotocin-induced diabetic Wistar rats. Asian Pacific J. Tropical Biomed., 1: 353-358. DOI: 10.1016/S2221-1691(11)60079-8

Swaminathan, J.K., M. Khan, I.K. Mohan, K. Selvendiran and S.N. Devaraj et al., 2010. Cardioprotective properties of Crataegus oxycantha extract against ischemia-reperfusion injury. Phytomedicine, 17: 744-752. PMID: 0171068

Turner, R.A. and P. Hebborn, 1965. Screening Methods in Pharmacology. 1st Edn., Academic Press, New York, pp: 332.

Walum, E., 1998. Acute oral toxicity. Environ. Health Perspect. 106: 497-503.
Wang, C.C., S.C. Changa, B.S. Inbaraja and B.H. Chen, 2010. Isolation of carotenoids, flavonoids and polysaccharides from Lycium barbarum L. and evaluation of antioxidant activity. Food Chem., 120: 184-192. DOI: 10.1016/j.foodchem..10.005

WHO, 1993. Research Guidelines for Evaluating the Safety and Efficacy of Herbal Medicines. 1st Edn., World Health Organization, Regional Office for the Western Pacific, Manila, ISBN: 9290611103, pp: 86.

Zuk, A., M. Targosz-T. Korecka and M. Szymonski. 2011. Effect of selected drugs used in asthma treatment on morphology and elastic properties of red blood cells. Int. J. Nanomed., 6: 249-257. DOI: 10.2147/IJN.S15802 